Pakistan Journal of Social Research

ISSN 2710-3129 (P) 2710-3137 (O)

Vol. 3, No. 3, September 2021, pp. 501-512,doi.org:10.52567/pjsr.v3i3.274

www.pjsr.com.pk

\title{
SOCIO-CULTURAL FACTORS OF SUSTAINABLE DRINKING WATER MANAGEMENT IN RURAL PUNJAB, PAKISTAN
}

\author{
Saif Ullah \\ PhD Scholar Department of Sociology University Sargodha, Sargodha \\ saifmalik.bk@gmail.com \\ Yasir Nawaz Manj \\ Associate Professor Chairman Department of Sociology, University of Sargodha, Sargodha \\ yasir.manj@gmail.com
}

\author{
Manzoom Akhter \\ Director (HR), University of Agriculture Faisalabad, Pakistan
}

\begin{abstract}
The water supply and sanitation sector has always been overlooked in the comparison to the other sectors both in the sense of budgetary allocation, in sustainability of development projects as well as execution of drinking water supply, sanitation schemes and provision of potable water strategies. The drinking water and sanitation system are closely linked with each other. The Government of Pakistan established the National Drinking Water Policy in September 2009, with the goal of providing clean and safe drinking water to the entire Pakistani population by 2025, including the poor and vulnerable, at a reasonable rate. The National Sanitation Policy of Pakistan was prepared in 2016, but recently conditions are adverse. In the Pakistan the sewerage systems are not only properly managed, out lived, inappropriate and leakages problems of sewer pipelines with major part of unserved population but also contribute towards water systems contamination and ground water as well as surface water contamination. The water for domestic utilization and wastewater of factories are mostly disposed of into rivers, streams and sometimes into water canals without any treatment of water in most of the conditions. There is also a conceptual issue with the traditional sewer systems due to leakages and seepage of sewage water is mixing in underground water as well as in food stuff. Some organic, inorganic elements and micronutrients are mixed up in the freshwater reservoir to a great extent that separation of the contaminant's elements and treatment of water for reusing purpose becomes complicated not only in the sense of technically but also economically unfeasible. Secondly, the micro-nutrients are mostly washed away with domestic and factories wastewater as well as from storm water, mixed into freshwater channels.
\end{abstract}

Keywords: Water Supply, Sustainable, contamination, ground water, Water Pollution, wastewater, Fresh Water. Safe Water

\section{INTRODUCTION}

After oxygen, water is the second most valuable nutrient. Approximately 700 million people do not have regular access to safe and clean drinking water. Around 35 percent of the world's population, or 2.5 billion people, do not have access to sanitary sanitation services. Every day, 1400 infants die and tens of thousands of adults contract infections as a result of a lack of water and sanitation services (WSS) (Sanitation and Water for all, 2013). Water and sanitation facilities are essential for society's health and have an impact on the economy; this all stems from healthy conditions and health-care difficulties. Gender equality may be activated through raising public awareness and reducing gender inequalities (AMCOW, 2011). According to Frederiksen (2005), international and regional strength may be defined by healthy active circumstances and lucrative economic activities, but also by stability and sustainability (Frederiksen, 2005). According to Guy Hutton in 2013, the cost of worldwide provision to drinking water the nexus is predicted 2 to 1 . The UN General Assembly open working group on sustainable development goals (SDG's) compendium of TST issues brief also endorsed it in October 2014, co-chaired by UNDSA and UNDP with other 40 members from UN (Hutton, 2013)(UN General Assembly, 2014). 
In 2014, the United Nations Children's Education Fund (UNICEF) and the World Health Organization (WHO) reported in a Joint Monitoring Program (JMP) for Water Supply and Sanitation that 91 percent of Pakistanis have easy access to drinking water sources and 48 percent have adequate sanitation facilities (WHO and Unicef, 2014).

Water quality is one of the most important issues in Pakistan's WSS delivery. According to Pakistan's Network for Consumer Protection, 60 percent of city inhabitants receive municipal water in 2005. Despite the fact that water is piped and contains chemicals and bacteria that are much over the government's level of safety for tap water, around $20 \%$ to $30 \%$ of the population lacks access to safe water (The Stimson Center, 2010).

The Sector-Wide Approach (SWA) was introduced by PRSP and WHO (2000) in response to criticism of country priorities on donor-driven projects, claiming that the projects' approach is unrealistic and not in line with the needs of developing countries with limited human and economic resources (WHO, 2014). WHO (2000) stated that a Sector-Wide Approach will be a trusted action for the investor, donor, and government with a close relationship in any investing government sector; this emphasised the importance of the government's presence in providing opportunity and competition for international donors and community to invest their resources linked to needs and necessity (WHO, 2014). This issue was seeded in the SWA and addressed the major necessity for all WSS, whether corporate, government, or non-government, to have a high degree of collaboration and coordination (WHO, 2014).

Sanitation and Water for All, (2013) stated that there is a need for collaboration between NonGovernmental Organizations (NGOs), the market, and users of public services. In addition to joint ventures, the report claims that the government strengthens the trust of both domestic and foreign investors (Sanitation and Water for all, 2013).

Rapid urbanization is occurring in emerging countries, particularly in Asia, as a result of industrialization and economic expansion. By 2020, more than half of Asia's population will be urbanized (UNDP, 1999). By 2030, it is predicted that $60 \%$ of the world's population will live in cities, with the majority of this expansion occurring in developing nations (UNCSD, 2001).

Increasing water demands as a result of fast population increase, urbanization, and industry are putting enormous strain on already scarce water supplies. With the concern of depleting water resources, emerging countries are also confronted with major issues such as contaminated drinking water, poor hygiene, and insufficient sanitation. As of 2004, around 1.1 billion people, or $18 \%$ of the world's population, lacked access to safe drinking water, and 2.6 billion people, or $40 \%$ of the world's population, lacked basic sanitation (UN Water, 2006). By the year 2025, this percentage will have risen to $50 \%$ (Robert Svadlenka, 2008). 39 percent of the 1.1 billion people without access to better water sources live in East Asia and the Pacific, 30\% in Sub-Saharan Africa, and 22\% in South Asia (HDR, 2006)

\section{Objectives of the Study}

1. To determine the awareness level among the people regarding drinking water and sanitation.

2. To search out the correlation between the safe drinking water and sanitation conditions and community participation.

3. To examine the causes of poor sustainability of water and sanitation conditions intervened through service providing Agencies.

4. To find out the gaps in existing institutional framework related to water and sanitation conditions.

5. To determine the impact of cultural factors in managing water and sanitation conditions.

\section{REVIEW OF LITERATURE}

A community's water, sanitation and hygiene practices are influenced by a variety of factors. Social standards, spiritual beliefs, traditions, access/convenience, community structure, experience and nurturing, and instruction are some of the effects. These aspects' names are not fixed, and they overlap in some areas; in related literature, these same aspects may be referred to by different names, such as social acceptance and dignity rather than social norms, and their relationships to hygiene and sanitation behavior, as well as each other, may be interpreted differently. However, similar ideas may be found in other literature, and their significance is evident, even though most literature merely declares their relevance without attempting any additional study. The socio-cultural components are 
examined and given below in order to importance, with the top ones regarded the most important to include when creating a water, sanitation and hygiene Program.

Traditions are another factor that impacts people's behavior; for example, many traditional activities include the use of herbal medicine. For the most part, residents in the settlements relied on herbs that were readily available in the area. Traditional medicine has been disregarded as more health facilities have opened and people have become more aware of, and many people now see it as an underdeveloped method of treating ailments. 'Now the new culture has replaced the old culture, and I don't want the old culture,' says one community member. This sort of thinking, however, is not due to specific programs like the KDWSP, but rather to the overall concept of development aid and engagement with the Western world. The behaviors of the West are seen as inferior to those of others, and this is passed on to less developed countries (LDCs). Herbal medicine was also employed for sanitary procedures, such as hand washing with an antibacterial leaf instead of soap, although these traditions have since died out due to their primitive nature. Because many people cannot afford soap, it would be more appropriate to continue washing hands with ashes or leaves rather than nothing.

More specifically, the international goal of universal water services (UN, 2015) demands equitable services for all but sustainability of local services may depend on user payments that result in exclusionary access, and thus compromise the principle of universality. Moreover, local priorities and choices may not confirm with set of institutional limits. Global values and experiences of uncertainty may be in conflict at the local level. Then culture comes in. The theory of socio-cultural viability also known as cultural theory (Douglas, 1994)

There is no such thing as flawless water and sanitation design, program, or technologies that will operate anyplace and with anybody. Instead, the most important thing is to take the time to understand the context in which the Conditions are being done. When constructing a water and sanitation Conditions, several different elements must be addressed.

One such component is the socio-cultural aspects addressed in this study, and which aspects will have the most effect will vary from location to location and scenario to situation. There is no onesize-fits-all solution that will always work. However, there are several key points or issues that must be handled more or less everywhere water and sanitation Conditions is performed. The initiative must be appropriate for the individuals who are being targeted. This implies that it must be appropriate for their economic as well as social and cultural circumstances. It must also be appropriate for their surroundings, including their access to drinking water and land, for example. So, in order for the software to function properly, it must be suitable. According to Carter, there is a need to address the problem of people's fundamental poverty in order to guarantee that they have discretionary resources to prioritize their water, sanitation, and hygiene situations.

Only $42 \%$ of the population has access to sanitary services, with 65 percent living in cities and 30 percent in rural towns. Only big cities like Lahore, Karachi, and Islamabad have sewerage systems (MOE, 2006). In Pakistan, sewage collection rates are not more than 50\% at the national level. Only about a quarter of the wastewater produced in rural regions gets collected (World Bank, 2006). During the previous 5 to 10 years, total access to flush and non-flush toilets has grown in all four provinces. Between 2001 and 2005, rural Punjab saw the most growth, increasing by $31 \%$ to 43\%. According to Pakistan Social Living Measurement (PSLM) estimates, 7.52 million households in Pakistan lacked access to hygienic sanitation (improved sanitation) in 2004-05, with 4.22 million households in Punjab alone (Khan \& Javed, 2007).

Every day, an estimated 2,000 million gallons of sewage are released into surface water bodies; with only approximately $10 \%$ of the collected sewage, being adequately treated (World Bank, 2006). Untreated home and industrial wastewaters are being discharged on land and into receiving water bodies in Pakistan, causing substantial damage to both groundwater and surface waterways. COD levels in most major water bodies, including Islamabad's Lehi nullah, Lahore's Ravi river, and Karachi's Lyari and Malir rivers, have surpassed the NEQs (National Environmental Quality Standards) of $150 \mathrm{mg} / \mathrm{L}$, indicating low oxygen levels and poor ecological health (World Bank, 2006). Existing procedures for designing water and wastewater treatment facilities are based on effluent water quality requirements without taking into account the receiving water bodies' waste assimilation capability, which may result in an uneconomical design. To arrive at a sensible and optimal solution, water quality management strategies must be developed and implemented while taking into account 
the water bodies' assimilative ability to satisfy the intended usage. This method will result in the development of stream water quality criteria.

Why is this case and why are the initiatives insufficient to ensure that everyone has access to safe water and sanitation? The question of socio-cultural issues within this area is part of the answer. These factors are frequently overlooked, if at all, and there is little understanding on the issue to assure appropriate and long-term water, sanitation and hygiene programs all over the world. Some essential variables, such as dignity and spiritual beliefs, have not been well researched, and the interrelationships between the various socio-cultural components and how they influence hygiene and sanitation behavior are unknown. The failure of initiatives is significantly hampered by a lack of knowledge of these factors. A project's chances of success and sustainability are little to none if it is not adapted to its surroundings. Looking back at the water, sanitation and hygiene history, Program's the sector has a very high failure rate; for example, many latrines are being utilized as storage across the world since they were not properly integrated and adapted to the users. Another technique is community led total sanitation (CLTS), which aims to 'inspire a sense of disgust and humiliation within the community (and) encourage them to take collective action to improve the sanitation situation'30. This technique was effective in Bangladesh, but it has had less success in other circumstances, according to (P. Bongartz, 2008). Bongartz (2003) offers reasons for the limited impact, such as societal divides and the use of social norms as limits (P.Bongartz, 2008). Ahmed, R. (2008) describes various alternative hygiene and sanitation promotion initiatives that were tested out in Bangladesh, including CLTS and CARE SAFER (Sanitation and Family Education Resource), which employed two models for hygiene behavior modification, the single channel and multi-channel models. The first approach targeted main recipients of hygiene promotion, such as well caretakers, whereas the second targeted a more diversified audience, such as children and males. Sanitation and hygiene, clean water, and diarrhea prevention and management are the three aspects of SAFER. A few short messages were utilized for each part. People are actively participating, so the messages are delivered in their own terms, which reduces the amount of time spent cleaning the water (Ahmed, 2008).

According to cultural theory water sustainable development Global progress towards the goal of universal, safely managed drinking water services will be designed by diverse nexus between water risks, values and social institutions. Mary Douglas' cultural theory to rural water point management and discuss its operation and maintenance in pluralist arrangements through social networking of different management cultures at scale (Koehler et al., 2018).

In the baseline year of the sustainable development agenda, 2015, 2.1 billion people lacked of safely managed drinking water services globally and 844 million people did not have an access to basic drinking water services (WHO \& UNICEF, 2017).

Achieving universal, safely managed and equitable water services (WHO/UNICEF, 2015) for rural water users needs progress in a number of areas. Often one or more of the requirements for them to be sufficient, safe, affordable, equitable and universal are not met depending on different managerial arrangements of water points and diverging risk perceptions of water users (WHO/UNICEF, 2015).

\section{MATERIALS AND METHODS}

The study was built around the primary data collected through conducting a sample survey and quantitative in nature. The survey is conducted across three districts of southern Punjab, Pakistan. In this study, the researcher used all available standards of sample survey and the complete information regarding socio-economic indicators of the target population, public perception about the effectiveness of management regarding water and sanitation conditions, water infrastructure and access to sanitation. Most of the explanatory variables of the study are related to water supply, quality of water and sanitation infrastructure. The study observed different sanitation facilities and different water categories across the study population. The study figured out the significant difference in improved and unimproved water facilities which are being used in the target population. The study declares the significant difference among the utilization of drinking water categories (improved and unimproved). 


\section{Sampling Process}

The nonprobability sampling design is widely used in surveys sampling. There are administratively 3 Divisions in Southern Punjab Pakistan i-e Bahawalpur, Multan and Dera Ghazi Khan and these 3 Divisions consist of total 11 districts in the South Punjab Pakistan such as Bahawalpur, Rahim Yar Khan, Lodhran, Multan, Vehari, Khanewal, Bahawalnagar, Dera Ghazi Khan, Muzaffargarh, Rajanpur and Layyah.

The multistage sampling technique was used for this study. At first stage 3 divisions were selected from the South Punjab. At the second stage 03 districts were selected from the sampling frame of 11 districts of the South Punjab 01 district was selected from each selected division through using systematic random sampling. At the third stage the sampling frame of the rural union councils from each of three districts was developed to draw a sample of 20 rural union councils from the sampling frame of 144 rural union councils of the three selected districts such as Vehari, Rahim Yar Khan and Rajanpur. At the fourth stage 520 respondents were selected through using the convenient sampling technique from 20 selected rural union councils of the study districts.

The focus of the study is to "characteristics of interest". Three districts were selected as a target population of the study. As the primary focus of the study is rural area, a sampling frames of rural union councils of the selected 03 districts are constructed based on the size criteria. The sampling frame 144 rural union councils 20 union councils were selected as the study population. The selection of 20 union councils was completed through using systematic sampling technique. The sampling ratio was calculated $\mathrm{kth}=\mathrm{N} / \mathrm{n}=20 / 144=7$ approximately. The fourth union council from the first seven union councils was selected and the second union council was selected at number eleven. The next union councils are selected after each seven union councils.

The respondents of the study were selected among all eligible members of the target population. The beneficiary members of the households of target population were the respondents of the study.

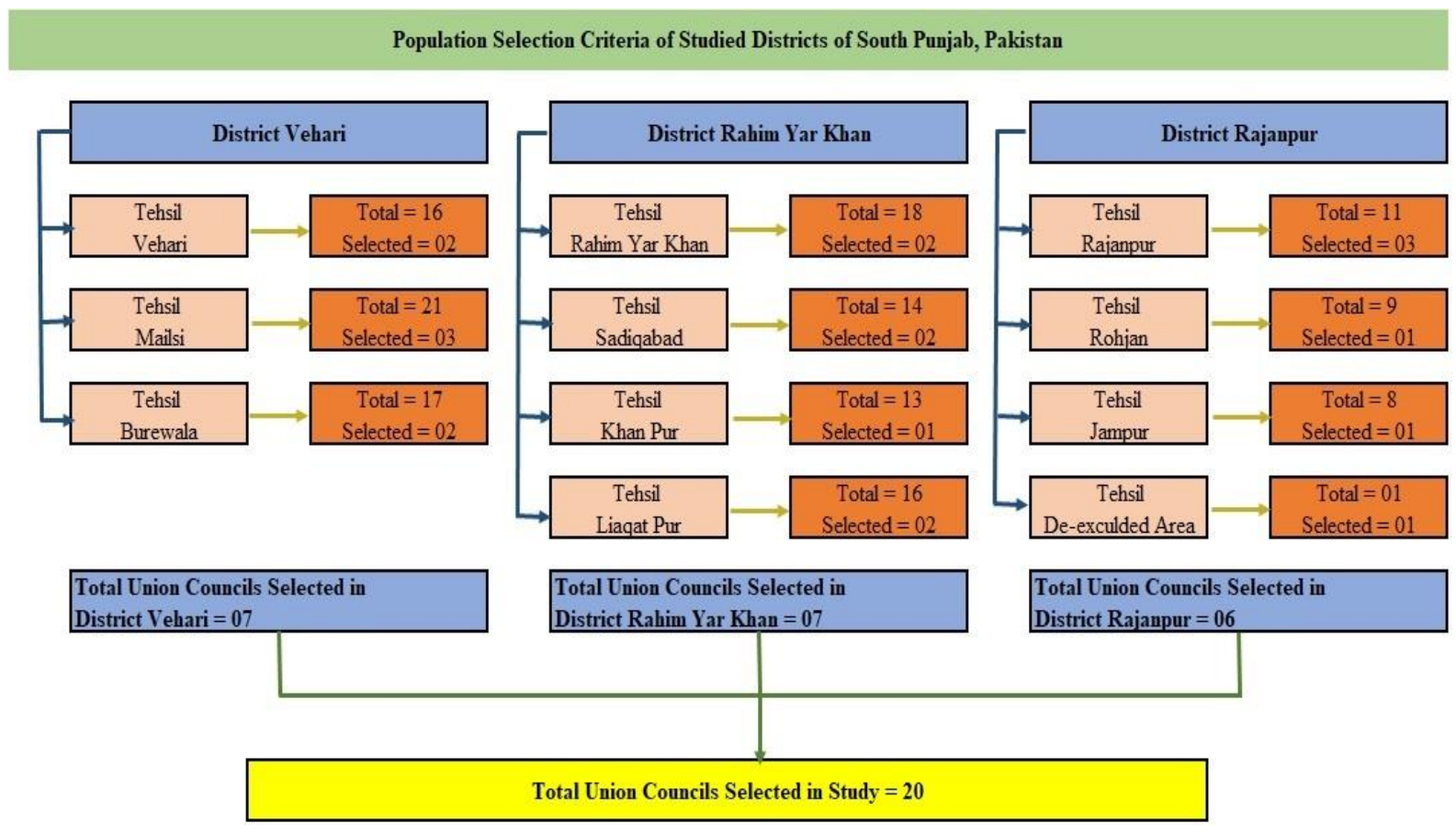

\section{Sample Size}

The sample size of this study is 520 respondents from selected 20 rural union councils of the three sampled districts.

The general linear regression equation is given by

$$
\mathrm{Y}=\mathrm{b}_{0}+\sum\left(\mathrm{b}_{\mathrm{i}} \mathrm{X}_{\mathrm{i}}\right)+\mu_{\mathrm{i}}
$$

Where $\mathrm{Y}$ is a continuous dependent variable (DV) and independent variables (IVs) Xi's are usually continuous but can also be binary. Other discrete domains u is a term used for 
the variance not explained by the model and is usually called "error". Individual dependent values denoted by $\mathrm{Yj}$ can be solved by modifying the equation a little $\mathrm{Yj}=\mathrm{b} 0+\sum(\mathrm{biXij})+\mathrm{u}_{\mathrm{j}}$ where $\mathrm{b}_{\mathrm{i}}$ is the rate of change in DV (Y) as a unit increase in independent variable $X_{i}$ holding other factors constant and $u_{i}$ is the stochastic disturbance term.

Logistic regression is also a generalized linear model (GLM). The logistic regression procedure uses the same basic formula but $\mathrm{Y}$ instead of the continuous is a binary outcome variable with two states either 0 or 1.

The equation for the probability of $\mathrm{Y}=1$ is given by:

$\mathrm{P}(\mathrm{Y}=1)=1 /\left(1+\exp \left(\mathrm{b} 0+\sum(\mathrm{biXi})\right)\right.$ Where independent variables $\mathrm{Xi}$ can be continuous or categorical (dichotomous). The coefficients bi's of the logistic regression can be exponentiated to obtain a change in odds of $\mathrm{Y}$ per unit change in $\mathrm{Xi}$.

\section{Conceptual Framework}

The conceptual framework is mostly developed in the light of literature review and theoretical framework. It is logically developed the relationship networking between the variables related to the research study (Sekaram, 1992). The categories of given below variables have been used in the present study. Described in figure 3.5

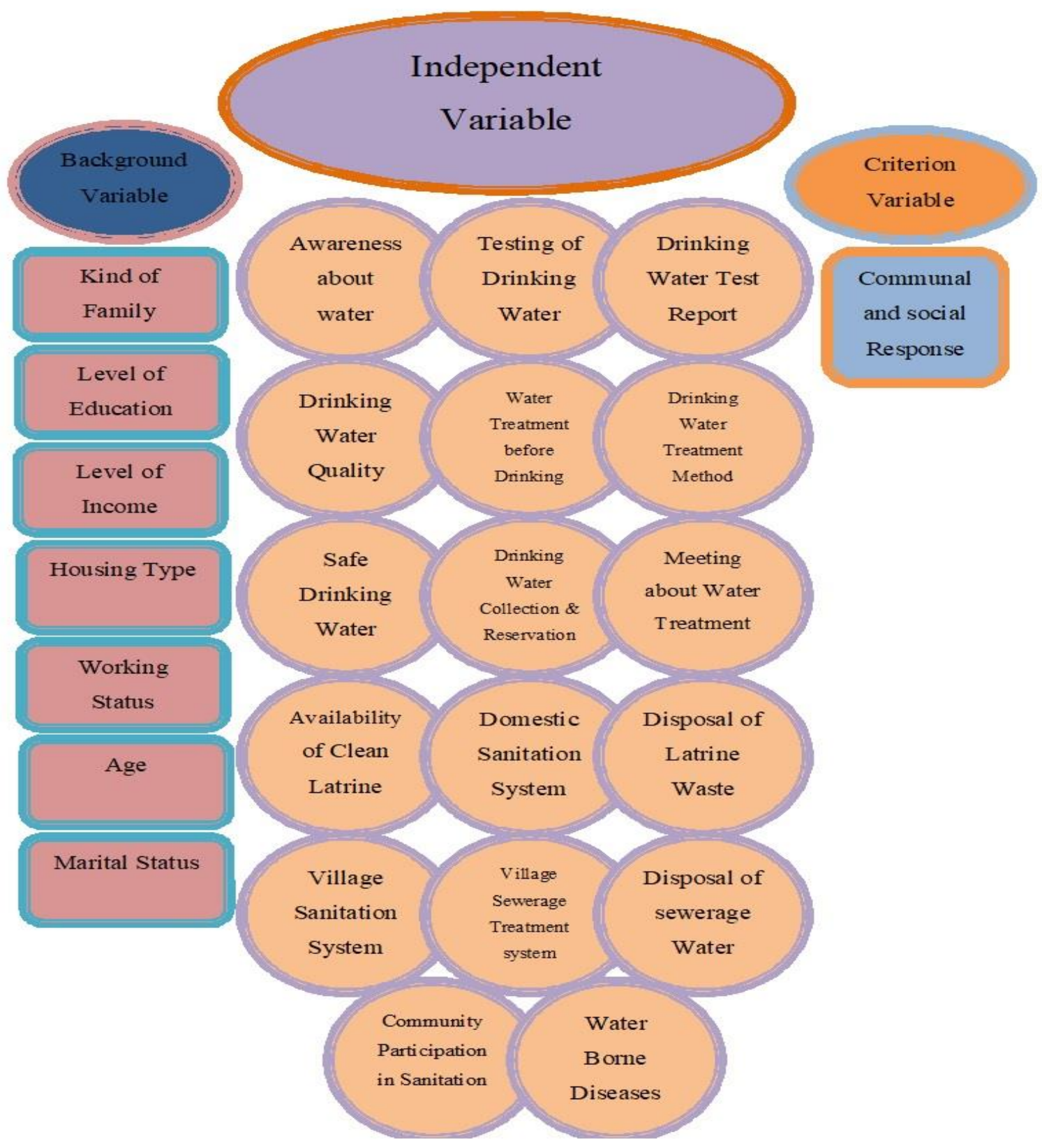




\section{DISCUSSION AND ANALYSIS}

The Millennium Development Goals stated that without a long-term right to water and sanitation, the objective of 2015 could not be attained in respect to 1990. The United Nations Development Program (UNDP) projected in 2006 that the aims for urban and rural water delivery, as well as urban sanitation, were on track. The 2006 National Sanitation Policy aims to provide universal sanitation access by 2025, which is one of the Millennium Development Goals. Pakistan's objective is to offer universal access to drinking water in an equitable, efficient, and sustainable way by 2025, according to the National Drinking Water Policy (NDWP) of 2009 (MOE, 2009).

According to a 2012 research by the Pakistan Council of Research in Water Resources, 88 percent of resourceful water delivery plans result in microbial contamination, rendering water unsuitable to drink (Alam, 2012). Pakistan receives significant peripheral money for water and sanitation improvements from the Asian Development Bank (ADB) and the World Bank, as well as contributions from Japan, England, and the United States. Furthermore, international nongovernmental organizations (NGOs) give direct assistance and investment. The World Bank subsidized a loan of US\$50 million for the Punjab Municipal Services Improvement Project (20062012) to improve municipal services in Punjab. The project is designed with around half of the funding set aside for water and sanitation. The World Bank committed to another US\$150 million credit for Punjab Cities Governance Improvement (2012), with a large portion allocated to water and sanitation provision.

Table No. 1 Source of Drinking Water across the Sampled Districts

\begin{tabular}{|l|c|c|c|c|}
\hline \multirow{2}{*}{\multicolumn{1}{c|}{ Source of Drinking Water }} & \multirow{4}{c|}{ Districts } \\
\cline { 2 - 5 } & Vehari & $\begin{array}{c}\text { Rahim Yar } \\
\text { Khan }\end{array}$ & RajanPur & Total \\
\hline Piped water into dwelling & $40(7.7)$ & $36(6.9)$ & $41(7.9)$ & $117(22.5)$ \\
\hline Piped water to yard/plot & $16(3.1)$ & $10(1.9)$ & $7(1.3)$ & $33(6.3)$ \\
\hline Public tap/standpipe & $7(1.3)$ & $3(0.01$ & $4(0.01)$ & $14(2.7)$ \\
\hline Tube well /borehole & $54(10.4)$ & $68(13.1)$ & $70(13.4)$ & $192(36.9)$ \\
\hline Protected dug well & & & $4(0.01)$ & $4(0.01)$ \\
\hline Unprotected dug well & & $1(0.001)$ & $1(0.001)$ & $2(0.004)$ \\
\hline Protected spring & & $3(0.01)$ & $1(0.001)$ & $4(0.01)$ \\
\hline Unprotected spring & & $1(0.001)$ & & $1(0.001)$ \\
\hline Rainwater collection & & $1(0.001)$ & $1(0.001)$ & $2(0.004)$ \\
\hline Bottled water & & $1(0.001)$ & & $1(0.001)$ \\
\hline Cart with small tank/drum & $1(0.001)$ & & $1(0.001)$ & $2(0.004)$ \\
\hline Tanker-truck & $26(5)$ & $27(5.2)$ & $21(4)$ & $74(14.2)$ \\
\hline Surface water & $16(3.1)$ & $14(2.7)$ & $14(2.7)$ & $44(8.4)$ \\
\hline Other & $13(5.2)$ & $9(1.7)$ & $8(1.5)$ & $30(5.7)$ \\
\hline Total & $173(33.3)$ & $174(33.4)$ & $173(33.3)$ & $520(100)$ \\
\hline
\end{tabular}

$x^{2}{ }_{(26)}=29.332, \mathrm{Phi}=0.238$ and Cramer's V= 0.168 (braces contain percentages of frequencies, $*$ and $* *$ indicate value is significant at $5 \%$ and $1 \%$ level of significance respectively)

The results of the above cross tabulation show that there are forty comprising nearly $8 \%$ of the respondents who are from district Vehari, and they use water supplied through pipe in their dwellings as source of drinking water. There are 36 comprising almost $7 \%$ of the respondents who are from district Vehari, and they use wipe water in their dwellings as source of drinking water. The majority (68 comprising 13\%) of the respondents uses borehole/tube well as source of drinking water at home and they belong to district Rahim Yar Khan. There are 192 comprising nearly $37 \%$ of the respondents who borehole/tube well as source of drinking water at home and they are from three study districts Vehari, Rahim Yar Khan and Rajanpur. The overall third majority (177 comprising $22.5 \%$ ) of the respondents uses water supplied through pipe in their dwellings as source of drinking in three study districts. The overall third majority (74 comprising 14\%) of the respondents uses water brought through Tanker-truck as main source of drinking water from three study districts.

The Pearson chi-square value is 29.332 is statistically insignificant which can be concluded as, there exist an insignificant association between the source of drinking water used in respondent's 
dwellings and their demographic districts. The respondent's demographic has a moderate but statistically insignificant effect on the source of drinking water used in respondents' dwellings. There exists a statistically insignificant correlation between "the source of drinking water used in respondent's dwellings" and their "demographic districts".

Table No. 2 Communal Participation in Sanitation and Water Supply across Study Districts

\begin{tabular}{|c|c|c|c|c|c|c|}
\hline \multirow{2}{*}{ Name of Districts } & \multicolumn{5}{|c|}{ Communal participation in all stages of sanitation and water supply } \\
\cline { 2 - 7 } & Very Poor & Poor & Don't Know & Good & Best & Total \\
\hline Vehari & $5(1)$ & $11(2.1)$ & $79(15.2)$ & $63(12.1)$ & $15(2.9)$ & $173(33.3)$ \\
\hline Rahim Yar Khan & $5(1)$ & $19(3.6)$ & $74(14.2)$ & $68(13.1)$ & $8(1.5)$ & $174(33.4)$ \\
\hline Rajanpur & $3(0.6)$ & $9(1.7)$ & $98(18.8)$ & $56(10.7)$ & $7(1.3)$ & $173(33.3)$ \\
\hline Total & $13(2.5)$ & $39(7.5)$ & $251(48.2)$ & $187(35.9)$ & $30(5.7)$ & $520(100)$ \\
\hline
\end{tabular}

$\chi^{2}{ }_{(8)}=13.716^{*}$,Phi $=0.162^{*}$ and Cramer's V $=0.115^{*}$ (braces contain percentages of frequencies, $*$ and

$* *$ indicate value is significant at $5 \%$ and $1 \%$ level of significance respectively)

The above table presents that there are 5 comprising $1 \%$ of respondents who are from Vehari district and they rated the Communal participation in all stages of sanitation and water supply as very poor. The fifteen percent of respondents didn't know about the Communal participation in all stages of sanitation and water supply, and they belong to Vehari. The majority (30 comprising 5.7\%) of the respondents from Rajanpur didn't know about the Communal participation in all stages of sanitation and water supply. There are 11 comprising $2.1 \%$ of the respondents who rated the Communal participation in all stages of sanitation and water supply as poor and they are from Vehari district. The majority (251 comprising $48.2 \%$ ) of total respondents did not know about the Communal participation in all stages of sanitation and water supply across the study population. The second highest proportion (187 comprising 35.9\%) of respondent's level of Communal participation in all stages of sanitation and water supply across the study population as good. Out of three study districts, majority of the respondents from Vehari district consider the best level of communal participation in all stages of sanitation and water supply.

The Pearson chi-square value of 13.716 is statistically significant. It can be concluded that as there is insignificant association between the Communal participation in all stages of sanitation and water supply and the respondents' locality. The cell has expected count $50 \%$ less than 5 . The effect size (Coefficient of Cramer's V) of the respondent's locality on communal participation in all stages of sanitation and water supply is weak ( 0.115 and statistically significant) and it can be concluded as the respondents' locality has a weak and significant effect on Communal participation in all stages of sanitation and water supply. The correlation between "the respondent's locality" and "Communal participation in all stages of sanitation and water supply" is weak (0.091) and statistically significant.

Table No. 3 Education and Main Sources of Drinking Water

\begin{tabular}{|l|c|c|c|c|c|c|c|}
\hline \multirow{2}{*}{$\begin{array}{c}\text { Main Source } \\
\text { of Drinking } \\
\text { Water }\end{array}$} & Illiterate & Primary & Middle & $\begin{array}{c}\text { High } \\
\text { School }\end{array}$ & $\begin{array}{c}\text { College } \\
\text { Degree }\end{array}$ & $\begin{array}{c}\text { University } \\
\text { Degree }\end{array}$ & Total \\
\cline { 2 - 8 } \\
$\begin{array}{l}\text { Piped water } \\
\text { into dwelling }\end{array}$ & $15) 2.9)$ & $25(4.8)$ & $28(5.4)$ & $18(3.4)$ & $12(2.3)$ & $19(3.6)$ & $\begin{array}{c}117(22 . \\
5)\end{array}$ \\
\hline $\begin{array}{l}\text { Piped water to } \\
\text { yard/plot }\end{array}$ & $3(0.6)$ & $7(1.3)$ & $9(1.7)$ & $8(1.5)$ & $2(0.4)$ & $4(0.8)$ & $33(6.3)$ \\
\hline $\begin{array}{l}\text { Public } \\
\text { tap/standpipe }\end{array}$ & & $4(0.7)$ & $3(0.6)$ & $1(0.2)$ & $3(0.6)$ & $3(0.6)$ & $14(2.7)$ \\
\hline $\begin{array}{l}\text { Tube } \\
\text { well/borehole }\end{array}$ & $31(5.9)$ & $32(6.1)$ & $45(8.6)$ & $27(5.1)$ & $24(4.6)$ & $33(6.3)$ & $\begin{array}{c}192(36 . \\
9)\end{array}$ \\
\hline $\begin{array}{l}\text { Protected dug } \\
\text { well }\end{array}$ & 0 & $1(0.2)$ & $1(0.2)$ & $1(0.2)$ & 0 & $1(0.2)$ & $4(0.8)$ \\
\hline $\begin{array}{l}\text { Unprotected } \\
\text { dug well }\end{array}$ & 0 & 0 & 0 & 0 & $1(0.2)$ & $1(0.2)$ & $2(0.6)$ \\
\hline $\begin{array}{l}\text { Protected } \\
\text { spring }\end{array}$ & $1(0.2)$ & 0 & $2(0.1)$ & 0 & 0 & $1(0.2)$ & $4(0.8)$ \\
\hline $\begin{array}{l}\text { Unprotected } \\
\text { spring }\end{array}$ & 0 & 0 & $1(0.2)$ & 0 & 0 & 0 & $1(0.2)$ \\
\hline
\end{tabular}




\begin{tabular}{|l|c|c|c|c|c|c|c|}
\hline $\begin{array}{l}\text { Rainwater } \\
\text { collection }\end{array}$ & 0 & $2(0.4)$ & 0 & 0 & 0 & 0 & $2(0.4)$ \\
\hline Bottled water & 0 & $1(0.2)$ & 0 & 0 & 0 & 0 & $1(0.2)$ \\
\hline $\begin{array}{l}\text { Cart with } \\
\text { small } \\
\text { tank/drum }\end{array}$ & 0 & $1(0.2)$ & $1(0.2)$ & 0 & 0 & 0 & $2(0.4)$ \\
\hline Tanker-truck & $11(2.1)$ & $9(1.7)$ & $203.8)$ & $9(1.3)$ & $13(2.5)$ & $12(2.3)$ & $\begin{array}{c}74(14.2 \\
)\end{array}$ \\
\hline Surface water & $5(1)$ & $7(1.3)$ & $6(1.1)$ & $10(1.9)$ & $4(0.8)$ & $12(2.3)$ & $44(8.4)$ \\
\hline Other & $3(0.6)$ & $6(1.1)$ & $10(1.9)$ & $3(0.6)$ & $4(0.8)$ & $4(0.8)$ & $30(5.7)$ \\
\hline Total & $69(13.2)$ & $95(18.3)$ & $\begin{array}{c}126(24.2 \\
)\end{array}$ & $77(14.8)$ & $\begin{array}{c}63(12.1 \\
)\end{array}$ & $90(17.3)$ & $\begin{array}{c}520(10 \\
0)\end{array}$ \\
\hline
\end{tabular}

$\chi^{2}{ }_{(65)}=53.881, \mathrm{Phi}=0.322$ and Cramer's $\mathrm{V}=0.144$ (braces contain percentages of frequencies, $*$ and $* *$ indicate value is significant at $5 \%$ and $1 \%$ level of significance respectively)

The above table presents that there are 15 comprising $2.9 \%$ of respondents who are illiterate, and they use piped water as main source of drinking water in their dwellings. The five percent of respondents educated up to middle level also uses piped water as main source of drinking water in their dwellings. The majority (192 comprising 36.9\%) of the total respondents irrespective of their education level uses borehole/ tube well water as main source of drinking water in their dwellings. There are 45 comprising $8.6 \%$ of the respondents who are educated up to middle level who reported that they are using borehole/ tube well water as main source of drinking water in their dwellings. The third majority (33 comprising 6.3\%) of the total respondents irrespective of their education level uses tanker-truck water as a main source of drinking water in their dwellings. The majority (33 comprising $6.3 \%$ ) of respondents who are university qualified, and they use bore hole/ tube well water as main source of drinking water in their dwellings while the second majority (12 comprising 2.3\%) of uses surface water as a main source of drinking water in their dwellings. It is clear from the above results that the majority of the respondents (283 comprising 54.4\%) use bore hole/ tube well water as a main source of drinking water in their dwellings and they have college education. The results also show that majority (44 comprising $8.4 \%$ ) of the respondents use surface water as main source of drinking water across the study population irrespective of their education level.

The Pearson chi-square value of 53.881 is statistically insignificant. It can be concluded that as there is insignificant association between the respondent's level of education and the source of drinking water being used in their dwellings. The cell has expected count $50 \%$ less than 5 . The effect size (coefficient of Cramer's V) of the respondent's level of education on the source of drinking water being used is weak ( 0.144 and statistically insignificant) and it can be concluded as the respondent's level of education has a weak and insignificant effect on and the source of drinking water being used in their dwellings. The correlation between "the respondent's level of education" and "and the source of drinking water being used in their dwellings" is weak (0.322) and statistically insignificant.

Table No. 4 Treatment done to make Water Safe for Drinking and Respondent's Education

\begin{tabular}{|l|r|r|r|r|r|r|r|}
\hline & \multicolumn{7}{|c|}{ Treatment done to make Water Safe for Drinking } \\
\cline { 2 - 8 } $\begin{array}{l}\text { Respondent's } \\
\text { Education }\end{array}$ & Boil & $\begin{array}{c}\text { Add } \\
\text { bleach/chlo } \\
\text { rine }\end{array}$ & $\begin{array}{c}\text { Strain it } \\
\text { through } \\
\text { a cloth }\end{array}$ & $\begin{array}{c}\text { Use a } \\
\text { water } \\
\text { filter }\end{array}$ & $\begin{array}{c}\text { Solar } \\
\text { disinfe } \\
\text { ction }\end{array}$ & $\begin{array}{c}\text { Kon't } \\
\text { Know }\end{array}$ & \multicolumn{1}{c|}{ Total } \\
\hline Illiterate & $9(1.3)$ & $10(1.9)$ & $3(0.6)$ & $19(3.6)$ & 0 & $28(5.3)$ & $69(13.2)$ \\
\hline Primary & $5(1)$ & $17(3.2)$ & $8(1.5)$ & $16(3.1)$ & 0 & $49(9.4)$ & $95(18.2)$ \\
\hline Middle & $7(1.3)$ & $19(3.6)$ & $7(1.3)$ & $23(4.4)$ & 0 & $70(13.4)$ & $126(24.2$ \\
& $8(1.5)$ & $10(1.9)$ & 0 & $7(1.3)$ & 0 & $52(10)$ & $77(14.8)$ \\
\hline High School & $6(1.1)$ & $10(1.9)$ & $2(0.4)$ & $7(1.3)$ & 0 & $38(7.3)$ & $63(12.1)$ \\
\hline College Degree & $19(3.6)$ & $8(1.5)$ & $3(0.6)$ & $12(2.3)$ & $2(0.4)$ & $46(8.8)$ & $90(17.3)$ \\
\hline $\begin{array}{l}\text { University } \\
\text { Degree }\end{array}$ & $54(10.4)$ & $74(14.2)$ & $23(4.4)$ & $84(16.1)$ & $2(0.4)$ & $283(54.4$ & $520(100$ \\
\hline Total & & & & & & & \\
\hline
\end{tabular}


$\chi^{2}{ }_{(25)}=51.245^{* *}, \mathrm{Phi}=0.314^{* *}$ and Cramer's V $=0.140^{* *}$ (braces contain percentages of frequencies, * and $* *$ indicate value is significant at $5 \%$ and $1 \%$ level of significance respectively)

The results show that there are 9 comprising $1.3 \%$ of the illiterate respondents who boiled the water to make it safe for dinking. The majority of the illiterate respondents did not know about the method of water treatment which makes the water safe for drinking. There are 17 comprising $3.2 \%$ of the primarily educated respondents who have reported that they add bleach/chlorine to the water to make it safe for drinking. The majority (49 comprising 9.4\%) of the primarily educated respondents did not know about the methods of water treatment. There are 7 comprising $1.3 \%$ of the respondents who boil the water to make it safe for drinking and they are educated up to middle level. The majority (70 comprising 13.4\%) of the respondents who did not know about the water treatment methods and they are educated up to middle level. There are 23 comprising $4.4 \%$ of the respondents who filter the water before drinking and they are educated up to middle. There are 10 comprising $1.9 \%$ of the respondents who reported that they add bleach/chlorine to the water before drinking and they are educated up to secondary level. There are 7 comprising $1.3 \%$ of the respondents who reported that they filter the water before drinking and they have secondary level of education. The majority (52 comprising 10\%) of the respondents educated up to secondary level did not know about the water treatment. There are 7 comprising $1.3 \%$ of the respondents who reported that they filter the water before drinking and they have college degree. The majority (38 comprising 7.3\%) of the respondents educated up to college level did not know about the water treatment. There are 19 comprising 3.6\% of the respondents who reported that they boil water before drinking and they are university qualified. There are 12 comprising $2.3 \%$ of the respondents who reported that they filter the water before drinking and they are university qualified. Surprisingly, the majority (46 comprising $8.8 \%$ ) of the respondents educated up to university level did not know about the water treatment.

The chi-square value of 51.245 is statistically highly significant which is concluded as there is statistically significant association between the respondents' level of education and the method of water treatment before drinking. The respondents' level of education has a weak and statistically significant effect on the method of water treatment before drinking. There exists a statistically significant correlation between "the respondents' level of education" and "the methods of water treatment before drinking".

\section{CONCLUSION}

The residents of the study areas are moderately satisfied from the cleanliness and safety of water at the point of distribution after the implementation of water, sanitation and hygiene project. The available sanitation facilities are not exclusively improved and the sewage water discharged into canal or ditches without treatment. The participation in sanitation campaigns, clean water campaigns and group meeting about sanitation problems is significantly low across the study population. The awareness about water, sanitation and hygiene is negligible. The conditions of the water supply and excreta disposal in terms of sustainability, low cost, health benefits and non-health benefits are at intermediate level after the water, sanitation and hygiene project implementation in their locality. The conditions of the hygiene promotion in terms of sustainability health benefits, non-health benefits and low cost are also at intermediate level after the implementation of the water, sanitation and hygiene project across the study area.

The respondent's locality has a weak but statistically significant effect on the laboratory testing of drinking water. The respondent's level of education has a moderate and significant effect on and the doing any treatment to the water before drinking. There is statistically significant association between the respondents' level of education and the method of water treatment before drinking. There is statistically insignificant association between the respondent's level of education and the attendance in the group meetings about water treatment. There is statistically insignificant association between the type of housing in which respondents resides and the main source of drinking water. The respondents' locality has a weak and statistically significant effect on the type of latrine in their dwellings. There exists a statistically significant correlation between "the local conditions" and "the sewage treatment before discharge".

The correlation between "the respondent's level of education" and "the purpose of domestic latrine facility" is weak and statistically significant. There is a significant association between "the type of respondent's housing" and "the availability of clean latrine at dwelling". There exist 
significant differences in clean and safe water at the point of distribution between Rahim Yar Khan and Rajanpur. There exists a short-term difference in water supply functionality in terms of physical, institutional or financial constraints among the three study districts. The average score of Vehari district is statistically different from Rahim Yar Kahn and Rajanpur in water supply functionality in short term and the conditions are better than both of these districts while there exist no difference between Rahim Yar Khan and Rajanpur. The Rahim Yar Khan is much better in effective and realistic plans for cost recovery of water supply from Vehari and Rajanpur.

\section{RECOMMANDATIONS / SUGGESTIONS}

Keeping in view the findings of study following suggestions and recommendations are being desired to implement at various levels for making an effective policy about water and sanitation sector:

- It is strongly recommended that the quality of water being provided to the communities need to be monitored at the source as well as the user end on regular basis.

- The Government with the collaboration of donors should create public awareness regarding the importance of management regarding safe drinking water and sanitation through media, NGOs, community networks and educational institutions.

- Resource allocation in water and sanitation sector must be done on need based criteria.

- There is dire need of legislation and legal frame work in water and sanitation sector and its implementation regarding the issues of water and sanitation sector.

- Local representatives of affected communities must be involved in the policy making process regarding water and sanitation issues.

\section{REFERENCES}

Alam, A. R. (2012). The Pakistan water quality crisis. The Express Tribune Pakistan. https://tribune.com.pk/story/349958/the-pakistan-water-quality-crisis

AMCOW. (2011). AMCOW Country Status Overviews Regional Synthesis Report.

Douglas, M. (1994). Risk and Blame: Essays in Cultural Theory. Routledge.

Frederiksen, H. D. (2005). Addressing Water Crisis in Developing Countries. Journal of Environmental Engineering, 131(5), 667-675. https://doi.org/10.1061/(ASCE)07339372(2005)131:5(667)

HDR. (2006). Human Development Report 2005-2006. In Undp (Vol. 36, Issue 3). https://doi.org/10.1177/004908570603600312

Hutton, G. (2013). Global costs and benefits of reaching universal coverage of sanitation and drinking-water supply. Journal of Water and Health, 11(1), 1-12. https://doi.org/10.2166/wh.2012.105

Khan, F. J., \& Javed, Y. (2007). Delivering access to safe drinking water and adequate sanitation in Pakistan. PIDE Working Papers, 30, 1-47.

Koehler, J., Rayner, S., Katuva, J., Thomson, P., \& Hope, R. (2018). A cultural theory of drinking water risks, values and institutional change. Global Environmental Change, 50(November 2017), 268-277. https://doi.org/10.1016/j.gloenvcha.2018.03.006

MOE. (2006). National Sanitation Policy, Ministry Of Environment, Government Of The Islamic Republic Of Pakistan Islamabad, Pakistan Table of Contents. In Ministry Of Environment. Islamabad, Pakistan. .(2009). National drinking water policy 2009.

P.Bongartz. (2008). Favourable and Unfavourable Conditions for Community Led Total Sanitation | Community-Led Total Sanitation. https://www.communityledtotalsanitation.org/resource/favourable-and-unfavourableconditions-community-led-total-sanitation

Robert Svadlenka. (2008). "Sustainable Sanitation Approaches for the Urban Poor, World Hunger Year (WHY), . http://www.worldhungeryear.org/default.asp

Rokeya Ahmed. (2008). 22 Journey towards changing behaviour: Evolution of hygiene education in Bangladesh.

Sanitation and Water for all. (2013). Progress on Sanitation and Drinking-Water 2013 Update World | ReliefWeb. https://reliefweb.int/report/world/progress-sanitation-and-drinking-water- 
2013-update

The Stimson Center. (2010). Case Study KARACHI: nor any drop to drink: water and governance in urban pakistan. The stimson center, Washington, DC, 2.

UN General Assembly. (2014). Tst Issues Briefs.

UN Water. (2006). Gender, Water and Sanitation: (Issues 26 May, 2006).

UNCSD. (2001). Indicators Of Sustainable Development : Framework And Methodologies (Issue 3).

UNDP. (1999). United Nations Development Report 1999. In Undp. Oxford University Press.

WHO., \& UNICEF. (2017). 2017 Annual Jmp Report.

WHO/UNICEF. (2015). WASH Post-2015: Proposed indicators for drinking water, sanitation and hygiene. World Health Organization, 1-8.

WHO and Unicef. (2014). Drinking Water and Sanitation Progress on.World Bank. (2006). World Development Report: Equity and Development. In WorldDevelopmentReport. 